This is a preprint of the Article Pajarito D., Degbelo A. \& Gould M., Collaboration or Competition: the impact of Incentive Types on Urban Cycling. International Journal of Sustainable Transportation, 2019.

The final version is available online at: https://www.tandfonline.com/doi/full/10.1080/15568318.2019.1627619

\title{
Collaboration or Competition: the Impact of Incentive Types on Urban Cycling
}

\section{Diego Pajarito - Auriol Degbelo - Michael Gould}

Diego Pajarito - Geotec research group, Department of Information Systems,

Universitat Jaume I, Castellón, Spain-ORCID: https://orcid.org/0000-0001-9458-

7436-Twitter: @diegopajarito - Research Gate:

https://www.researchgate.net/profile/Diego_Fabian_Pajarito_Grajales

Auriol Degbelo - Institute for Geoinformatics, University of Münster, Münster,

Germany-ORCID: https://orcid.org/0000-0001-5087-8776 - Twitter: @aurioldegbelo

- Research Gate: https://www.researchgate.net/profile/Auriol_Degbelo

Michael Gould - Geotec research group, Department of Information Systems,

Universitat Jaume I, Castellón, Spain - ORCID: http://orcid.org/0000-0002-6431-1794

-Twitter: @Omgould

Castelló, Spain, Avda. Sos Baynat S/N, 12071, pajarito@uji.es

Provide short biographical notes on all contributors here if the journal requires them. 


\title{
Collaboration or Competition: the Impact of Incentive Types on Urban Cycling
}

\begin{abstract}
Bicycling is an important mode of transport for cities and many cities are interested in promoting its uptake by a larger portion of the population. Several cycling mobile applications primarily rely on competition as a motivation strategy for urban cyclists. Yet, collaboration may be equally useful to motivate and engage cyclists. The present research reports on an experiment comparing the impact of collaboration-based and competition-based rewards on users' enjoyment, satisfaction, engagement with, and intention to cycle. It involved a total of 57 participants in three European cities: Münster (Germany), Castelló (Spain), and Valletta (Malta). Our results show participants from the study reporting higher enjoyment and engagement with cycling in the collaboration condition. However, we did not find a significant impact on the participants' worldview when it comes to the intentions to start or increase cycling behaviour. The results support the use of collaboration-based rewards in the design of gamebased applications to promote urban cycling.
\end{abstract}

Keywords: urban cycling; gamification; engagement; mobile apps; collaboration; competition

Subject classification codes:

\section{Introduction}

Improving urban mobility is a tough challenge to tackle in cities around the world. Among the conventional modes of transport, urban cycling is one of the most environmentally friendly since it produces almost zero carbon footprint (Bonham \& Johnson, 2015). Different communities and advocacy groups promote utilitarian cycling as well as the way it benefits urban mobility (Garrard, 2015). Such groups have also experimented with information technologies (e.g. web maps, mobile apps, social networks, video platforms, among others) as means to improve the way cyclists communicate their feelings when cycling, especially with city authorities, or how they 
connect with other mates. In some experiments, location has been considered to describe cycling activities and to assess the impact of advocacy groups when it comes to their action areas (Gössling, 2018).

Mobile applications such as Strava, Endomondo, Fitbit, or Polar offer functionalities for recording cycling time, speed, slope, altitude, or burned calories. We surveyed mobile applications for cycling having more than 10.000 downloads at the mobile stores. Only three apps (Bike Citizens, "Map my Ride” and Biko) target urban cyclists or people using bicycles as a mode of transportation. These applications mainly use competition strategies (i.e., they entice the user to outdo against other riders or achieve self-defined goals) to motivate and engage users by rewarding the highest performance (Pajarito \& Gould, 2017) (e.g., offering badges for recording more than 10 $\mathrm{km}$ per day or after getting the cycling speed record). On the other hand, collaboration, where users aim to achieve a common goal or benefit for a group, may be an interesting alternative to motivate and engage users (McNutt, 2014).

Collaboration underlies popular strategies such as crowdsourcing, citizen science, civic engagement or tactical urbanism (Lydon et al., 2016) among others. A good example of collaboration is when participants act as team members to complete a goal (Halko \& Kientz, 2010). This is the case of collective mapping of bicycle paths or other types of cycling infrastructure using OpenStreetMap. Collaboration has also been used to make communities understanding urban issues, fostering then activism and proactivity. For example, citizens can be directly engaged in the measurement of noise and air pollution in the city (Waag Society, 2018); in painting potholes, temporal bike lanes, or temporary parking places (Lydon et al., 2016). Also, citizens can voluntarily choose pro-social routes to decrease their marginal impact on urban transport (Miller, 2013). 
The potential benefits of engaging people in sustainable transport practices, especially urban cycling, can grow further by adopting multiple strategies. In their work, Halko and Kientz (2010) investigated correlations between types of persuasion strategies (e.g., extrinsic/ intrinsic motivators, positive/ negative reinforcement, cooperative/competitive social persuasion) and personality traits (e.g., authoritative, non-authoritative) which make them more likely to succeed. Their study found a significant relationship between personality traits and persuasion strategies, suggesting the need for customized persuasion techniques based on personality.

The emphasis of existing cycling applications on competition as persuasion strategy limits the number of potential users they may reach. There is also a dearth of studies investigating the impact of persuasion strategies based on collaboration. This work aims at addressing this gap, focusing on the use of collaboration-based rewards as incentives, along with geo-games to encourage urban cycling.

Our experiment compared the impact of collaboration versus competition-based rewards provided by geo-games on the levels of intention, satisfaction, and engagement with urban cycling. For the study presented in this article, we define urban cycling as the use of bicycles for a commuting purpose (i.e., cycling as a mode of transportation).

The low use of mobile technologies for urban cycling (compared to competitive cycling usually practised outside the urban areas), and the willingness of cities to encourage citizens in more sustainable modes of transport call for studies which help better understand the factors affecting citizen engagement with urban cycling. City governments may want to know the reasons for which more people do not bike to work or school, or how they could progressively increase bike usage. Considering geospatial technologies can facilitate the analysis of mobility patterns while providing new and 
valuable data about urban cycling (Gössling, 2018), the experiment presented later on the use of a geospatial mobile application.

Our mobile application provides user feedback including an estimation of the data contributed to the overall experiment as a percentage. The aggregated dataset can potentially help city stakeholders to assess cycling conditions, to improve urban facilities and plan cycling infrastructure. This new approach could provide a better fit with the interest of city government or advocacy groups' when it comes to promoting urban cycling, decreasing congestion and pollution, optimisation of public space and parking, and reduction in the use of cars (Wojan \& Hamrick, 2015).

The paper continues with a compilation of the related work on urban cycling and mobile geospatial technologies, a description of our research approach, participants, the mobile geo-game and the analysis tasks. Finally, it presents the results of the experiment as well as their implications for engaging urban cyclists.

\section{Related Work}

After being the dominant mode of transport in the early years of the twentieth century, then declining and returning, urban cycling has again become a popular mobility alternative for today's dense and chaotic cities (Oldenziel, Emanuel, de la Bruheze, \& Veraart, 2015). Bicycles are now part of the urban culture and complements the existing transport alternatives by reducing the overall carbon footprint. At the same time, urban cycling has served as a playground for testing sensors, micro-computers, mobile applications, and other tools within the world of the Internet of Things (IoT) (Pucher \& Buehler, 2008, 2017). The following sections briefly introduce previous work on urban cycling and mobile geospatial technologies. 


\section{Urban cycling}

Due to the efficiency of bicycles in the use of space, fuel consumption and CO2 emissions (Handy, van Wee, \& Kroesen, 2014), some cities invest substantial resources to make them more attractive for citizens (Nielsen, Skov-Petersen, \& Agervig Carstensen, 2013). City governments have mainly adopted infrastructure-based strategies such as more and better bicycle paths (Pucher, Dill, \& Handy, 2010), parking facilities for bicycles (Garrard, 2015), and public bicycle-share systems (Pucher \& Buehler, 2017). Apart from the well-known strategies adopted by Copenhagen (Nielsen et al., 2013) or Amsterdam (Pucher \& Buehler, 2008), many other cities are fostering urban cycling through a wide range of policies and programs without seeking to become world leaders (Pucher et al., 2010). The three cities selected for our study have relevant sections for urban cycling in their published mobility plans: Castelló in its 2007 urban sustainable mobility plan (Ayuntament de Castelló, 2016), Münster in its 2009’s mobility master plan projected until 2025 (Münster Stadt, 2017), and Malta in its 2010 transport master plan (Land Transport Authority, 2013).

Bicycle enthusiast groups have also appeared to promote the use of bicycles worldwide, share their experiences and advertise the benefits of urban cycling adoption for the environment, mobility and urban mobility (Martinez Tabares, 2017). The Amsterdam example is a well-documented case where active citizen participation formed in 1970 demanded bicycle and pedestrian-friendly development of the city; positive consequences of such events are still evident today in the city (Oldenziel et al., 2015). The power of citizens who demanded that the city authorities stopped building car infrastructure and protected pedestrians, cyclists and especially children, has made Amsterdam one of the bicycle-friendly cities in the world. This power also demonstrates 
the decisive role of citizens in urban cycling promotion, not only in Europe but worldwide (Garrard, 2015; Horton, 2006).

Cities and advocacy groups normally use traditional media and public events to promote the use of bicycles and engage citizens with physical activities. Through these promotional actions, advocacy groups aim to improve living conditions while citizens enjoy greener open spaces and infrastructure for walking and cycling (Pooley et al., 2011). Additionally, some cities deploy massive events for cyclists such as car-free streets either during holidays or as part of sustainable transport campaigns to showcase the benefits of building bicycle-friendly environments (Cervero, Sarmiento, Jacoby, Gomez, \& Neiman, 2009; Torres, Sarmiento, Stauber, \& Zarama, 2013). In the last decades, some cycling advocacy groups have run "Critical Mass" events to claim better cycling conditions to the town halls (Carlsson, 2002). Although there are advocacy groups in many cities, their lobbying success strongly depends on policy makers and local authorities with whom they negotiate (Pucher et al., 2010). Unfortunately, local authorities usually lack urban cycling data (Gössling, 2018) and therefore difficulties to either effectively develop adequate cycling infrastructure or promote bicycle commuting.

When it exists, data about cycling is not always accessible, is highly aggregated or comes from overly simplified descriptions in general transport surveys (Gössling, 2018). High-quality information such as travel diaries, trip inventories, or GPS tracks can be used to improve the promotion of cycling and the planning of its infrastructure (Braun et al., 2016). Therefore, the interest in data collection alternatives have grown, mainly due to the capabilities of current mobile phones (Barratt, 2017), location-based services (LBS) and the need for representing and modelling mobility conditions in cities (Pooley et al., 2011; Yeboah \& Alvanides, 2015). 


\section{Mobile geospatial technologies for urban cycling}

Geospatial technologies consider geographical space as the primary variable in transport analysis methods (Miller \& Shaw, 2001). Cycling, as an individual mode of transport, requires data at a finer scale and as detailed as the data provided by current mobile technologies (Norris, 2015; op den Akker, Jones, \& Hermens, 2014; Shin et al., 2015). Tracking cycling activities is technically viable nowadays and can provide reliable information on mobility patterns (Chen, Shen, \& Childress, 2018; Yeboah \& Alvanides, 2015).

Examples of activities for which data collection through mobile technologies is useful include the identification of travel patterns (Wang, Palm, Chen, Vogt, \& Wang, 2016), network coverage (Zahabi, Chang, Miranda-Moreno, \& Patterson, 2016), infrastructure optimization (Calvey, Shackleton, Taylor, \& Llewellyn, 2015), corridors delimitation (Yeboah \& Alvanides, 2015) or routing (Segadilha \& Sanches, 2014). Moreover, the combination of mobile and geospatial technologies just started to improve traditional data collection methods by geo-locating questionnaires, or automatizing surveys and travellers' diaries (Montini, Prost, Schrammel, RieserSchüssler, \& Axhausen, 2015).

Researchers are exploring future trends in urban cycling such as potential users of electric bikes in Norway (Fyhri, Heinen, Fearnley, \& Sundfør, 2017), perceived comfort and satisfaction with cycling infrastructure in the United Kingdom (Calvey et al., 2015), or integrated transmedia to attract, engage and guide new cyclists with music (Albrecht, Väänänen, \& Lokki, 2016). Additionally, researchers are beginning to evaluate the role of serious games in urban cycling promotion, and so publications in that area, while still scarce, are emerging (Pajarito \& Gould, 2017). 
To classify current mobile applications for cyclists, we surveyed those having more than 10.000 downloads in app stores, (see Appendix D). We found that only "Bike Citizens", "Map my Ride" and "Biko" focused on urban cycling, whereas "Strava" and many others are used mainly for longer, extra-urban rides. We also found that most applications use competition-based rewards (e.g., achieving the shortest time, the longest ride, the fastest speed or other outstanding goals) as their gamification strategy, see Table 1.

Apart from the surveyed applications using gamification to engage citizens, at least two aimed to promote urban cycling but used gamification based on neither competition nor collaboration. First, the city of San Francisco developed and used the application "Cycle tracks" to record trips from more than 300 volunteers between November 2009 and April 2010 (Hood, Sall, \& Charlton, 2011). Afterwards, the city of Seattle used the same application and recorded trips from more than 190 volunteers between 2009 and 2014 (Chen et al., 2018). The second application "GreenBikeNet", used ZigBee technology to create a wireless network for social interaction with realtime notifications between cyclists (Abu-Sharkh \& Dabain, 2016).

There is a growing market for tracking sporting activities (Wolff et al., 2017), with popular brands like "Fitbit" that offers devices, applications and information systems to store competitive fitness information (Tomitsch \& Haeusler, 2015). Two tech-based companies, Strava and Endomondo, use social interaction and geo-located data to engage users with sports (Barratt, 2017; Spillers \& Asimakopoulos, 2014). the interest of cities and tech-companies in understanding how people use bicycles and their preferred streets and times (Claudel, Nagel, \& Ratti, 2016; Gössling, 2018; Norris, 2015), has provoked an increasing demand for cycling data. Unfortunately, open alternatives such as the Open Cycle Map cannot supply such data 
because their focus is on existing infrastructure-related information rather than on data describing people behaviour (Sultan, Ben-haim, Haunert, \& Dalyot, 2015; Yeboah \& Alvanides, 2015). Therefore, cities, tech-companies and researchers started to combine gamification (Barratt, 2017; Navarro et al., 2013), citizen science strategies (Attard, Haklay, \& Capineri, 2016; Haklay, 2013) with mobile phone applications to not only understand cyclists' behaviour but also to engage people with crowdsourcing cycling data collection.

New and increasingly popular bicycle rental services could provide new opportunities to engage people with cycling as well as with cycling data collection (Gössling, 2018; Pucher et al., 2010). The integration between bicycle rental services and location-based technologies (National Geospatial Advisory Committee, 2015; Zeile, Resch, Loidl, Petutschnig, \& Dörrzapf, 2016) would evolve into customised citizenoriented engagement rather than one-size-fits-all solutions (Dill \& McNeil, 2012).

\section{Research method}

Our hypothesis is that collaboration-based rewards in mobile gamified applications would lead to a higher increase in intention, satisfaction, and engagement with urban cycling than competition-based rewards. Consequently, the experiment followed a between-groups design to measure the impact of virtual rewards provided by geo-games on the levels of intention, satisfaction, and engagement with cycling.

Participants were randomly divided into two balanced groups. They used an application with either an interface featuring collaboration (group A) or competitionbased rewards (group B). The independent variable (i.e., factor controlled during the experiment) was the "type of reward used for motivation" while the dependent variables (i.e., factors measured) were the overall satisfaction of the participants, their intention to use the bicycle, their engagement with cycling during the experiment as well as their 
enjoyment competing against or collaborating with other participants during the experiment. Table 2 summarises the independent and dependent variables considered during the study.

Intention to cycle was measured in pre-post questionnaires following the theory of planned behaviour adapted by Gatersleben and Haddad (2010), asking participants to rate the statement "My intention to use a bicycle is" on a Likert-like scale (Likert Rensis, 1932) with values ranging from "Very weak" to "Very strong", as shown in Appendix A. Satisfaction was measured via two means. First, we used a postquestionnaire in which participants were asked "how satisfied / dissatisfied in general you were with cycling during the experiment". Participant responses were codified in a Likert-like scale with values ranging from "Very dissatisfied" to "Very satisfied", as shown in Appendix B. Second, we identified the perceived sentiment of participants (e.g., positive, neutral or negative) related to the words they used for tagging bicycle trips as described by Pang \& Lee (2008). For example, a participant who tagged a trip with the word "inspiring", which has a positive meaning associated, would mean positive sentiment polarity while the word "dangerous" would mean negative sentiment polarity.

Engagement with cycling during the experiment was assessed through two complementary means: the number of trips, and the number of tags recorded during the experiment. We also compared the levels of enjoyment between the two groups by using a post-questionnaire in which participants were asked to rate the statements "I found collaborating with other cyclists enjoyable" (for the collaboration condition) and "I found competing against other cyclists enjoyable" (for the competition condition) on a Likert-like scale with values ranging from "Strongly disagree" (-3), "Strongly agree" (3). 
To get background information about the participants' overall attitude towards cycling, we used a modified version of Pooley's questionnaire (Pooley et al., 2011), shown in Appendix C. Table 3 summarizes participants' attitudes towards cycling. Although we aimed to classify participants' cyclist profile, and Gatersleben and Haddad (2010), as well as Dill and McNeil (2012) offered questionnaires, these did not fit into our design since they were either very long or not applicable to the European context. Fig. 1 presents a methodological approach of the experiment.

\section{Recruitment procedure}

The study recruited 20 participants in each city through printed posters, flyers, messages on social media and emails to the local cycling advocacy groups. Participants were required to be Android phone users as well as to meet the researchers to install the application, receive the instructions for the experiment, and comment on their experience with researchers. Participants had three tasks: i) complete the first questionnaire about demographics, cycling profile, mobile technologies, satisfaction and intentions to cycle; ii) install the geo-game, record each bicycle trip and describe it with up to three tags upon arrival; iii) complete the second questionnaire at the end of the experiment to provide feedback.

\section{The Android app: Cyclist GEO-C}

The "Cyclist Geo-C" geo-game allowed participants to track their bicycle trips and tag them upon arrival with up to three words or tags. The geo-game offers two different interfaces as seen in Fig. 2. First, the collaboration-based interface rewards participants according to their contribution to the total number of trips and tags. The collaborationbased rewards were higher percentages given to participants with more trips and tags recorded during the experiment. Second, the competition-based interface rewards 
participants according to the number of trips and tags compared to the recordings of other participants in the city. The competition-based rewards were higher positions on a leader board given to participants recording the higher number of trips and tags.

Cyclist Geo-C ${ }^{1}$ randomly assigns one of the two interfaces to a new participant and provides different modules to control trip records, choose up to three tags upon arrival (i.e., the participant chooses from either a pre-defined list available in Table 5 or manually types a new tag), set up a user profile, check the dashboard, and view the leader board (visible only for the competition-based interface). The application supports four languages: English, European Spanish, German and Catalan. It has a modular and open architecture, and is part of the Open City Toolkit: a collection of tools, processes, specifications and guidelines to empower citizens to participate in and shape the future of their cities (see (Degbelo, Bhattacharya, Granell, \& Trilles, 2016; Degbelo, Granell, et al., 2016)).

\section{Data collection and analysis}

The experiment produced two main datasets: a set of answers from the pre-post questionnaires, and a set of trips, coordinates, and tags recorded through the geo-game. The analysis consisted of descriptive statistics and the comparison of mean and variance of the answers for satisfaction, intention to use the bicycle, engagement with cycling and enjoyment with collaborating or competing. We statistically tested the normal

\footnotetext{
${ }^{1}$ Application Available at: https://url.to.be.added.google.com/store/apps/details?id=geoc.uji.esr7.mag_ike. The source code of the applications is available at: https://github.com/diegopajarito/Mag-ike. The video explaining the basic functionalities is available at: https://www.youtube.com/watch?v=QKMwNfOcNK4.
} 
distribution of each group of answers to measure the dependent variables (Shapiro \& Wilk, 1965). Next, we statistically compared their means and distribution with either tStudent (Stein, 1945) or Wilcoxon (Gehan, 1965) tests, and estimated the Cohen size of the effect (Lakens, 2013).

For the second part of the analysis, we extracted the geometric trajectories recorded during cycling trips using the Python Geojson library. Those trajectories were associated with the geographic coordinates as well as with the start-stop time, altitude, precision, and cycling speed. Consequently, they are compatible with geographic information systems (GIS) and related cartographic reference systems.

Considering the usual urban cycling scenario (Bigazzi, 2017), we classified the duration and length of bicycle trips into four categories: i) Valid trips, trips that lasted between 0.5 and 300 minutes and covered more than 30 meters; ii) Valid in time, trips that lasted between 0.5 and 300 minutes but did not have location records; iii) Valid in length, trips that covered more than 30 meters but the app did not record any start and stop time, and iv) Non-Valid trips, for trips that did not fit into the previous categories.

We also classified the tags recorded by participants based on the list of 24 predefined tags shown in the app available in Table 5. We considered a positive, neutral or negative sentiment associated with each tag, also known as sentiment polarity (Pang \& Lee, 2008) and linked such polarity to the level of satisfaction during the trip.

\section{Deployment of the experiment}

The experiment was deployed in three European cities: Münster in Germany, Castelló in Spain, and Valletta in Malta. The cities were selected mainly due to the contrasting cycling environment, and also because of the existing relationships with research centres and cycling advocacy groups willing to collaborate with the research. The city of Münster is located in the North Rhine-Westphalia region, northwest Germany, with 
300.000 inhabitants, mostly flat, and with an extended and high-quality network of dedicated bicycle lines; 39\% of the trips in Münster are made by bicycle (Münster Stadt, 2017).

The city of Castelló is part of the Valencian Community on the Mediterranean coast of Spain, with 180.000 inhabitants. It is mostly flat, and has a network of bicycle lines that covers the main corridors of the city and connects with the surroundings; about $2 \%$ of the trips in Castelló are made by bicycle, and the tendency grew during the last years (Ayuntament de Castelló, 2016).

The city of Valletta and the surrounding urban area of Malta is a network of small cities within the Mediterranean island with multiple bays and low hills. It has more than 400.000 inhabitants, and almost no cycling infrastructure apart from dedicated bus lines shared with cyclists; less than $1 \%$ of the trips in Malta are by bicycle (Land Transport Authority, 2013).

\section{Results}

The results of the experiment are presented in three sections: intentions to cycle, satisfaction, and engagement with cycling. Although results showed no statistically significant difference in participants' intentions to cycle or satisfaction with cycling after the experiment, they provide insights into the differences between the two conditions. We found higher levels of satisfaction with cycling in the collaboration condition and multiple participants engaged in recording trips and tags after the experiment, especially those from the competition condition. Finally, we contrast participants' profile with the levels of enjoyment, satisfaction, and engagement with cycling. 


\section{Participants}

Fifty-seven participants (19 in Münster, 20 in Castelló, and 18 in Malta) joined the experiment during the summer-autumn 2017: in Münster from September 18 to October 6, in Castelló from October 16 to November 3, and in the urban area of Malta from November 9 to 30 . Each participant received a nominal $€ 10$ reward after finishing the tasks. Participants were aged between 15 and 58 years (mean 33.4, median 32.5), were mainly singles (23 single and 12 in a relationship but not living together), and included 24 female participants (42\%). Table 3 shows participants' profiles in greater detail.

Participants from Castelló and Valletta provided similar answers: they agreed on their positive perception of cycling, sentiments such as freedom, relaxation or safety during cycling; as well as the benefits of bicycles in safety, health, and lower pollution. Participants from Münster reported quite different answers when it came to cycling infrastructure and traffic. In particular, they had lower agreement with the need to improve cycling infrastructure and facing difficulties at intersections. (See Questions: "More cycle lanes would make me feel safer", "It would be a bad experience using the existing roads", and "It would mean I have to negotiate difficult road junctions"). Table 4 lists cycling profile questions and average answers for each city.

\section{Intention to cycle}

We compared the reported intention to cycle before and after the experiment. First, we did it for all participants and then for the two conditions. Using participants answers on the Likert-like scale with values ranging from "Very Weak" (Scale value: -3) and "neutral" (Scale value: 0) to "Very Strong" (Scale value: 3), we did not find a statistically significant difference in the intentions before and after. We also compared participants' intentions to cycle at each experiment condition (see Table 6): before and 
after the experiment, and then, among the two conditions. We did not find any statistically significant difference in either case. The values were before and after very close to the scale values for "Very Strong". In short, the experiment did not lead to changes in participants' intentions to cycle.

\section{Satisfaction with cycling}

We compared satisfaction with cycling during the experiment for the two conditions $(\mathrm{Q}$ : "Indicate how satisfied / dissatisfied in general you were with: cycling during the experiment" and a Likert-like scale with values ranging from "Very dissatisfied", value: -3; to "Very satisfied", value: 3). Participants reported slightly higher (i.e., 8\%) satisfaction with cycling during the experiment in the collaboration condition (mean collaboration: 2.5 , mean competition: 2.296. Wilcoxon Test: $\mathrm{W}=343.5, \boldsymbol{p}<0.306$; $95 \%$ confidence interval $[-0.29,0.87])$, but the difference was not statistically significant.

We used the tags recorded through the geo-game as a second tool to measure participants' satisfaction with cycling during the experiment. We classified the 791 tags recorded by participants according to their sentiment polarity into: 273 (34.5\%) positive; 284 (35.9\%) neutral; $192(24.4 \%)$ negative; and 41 (5.2\%) without any sentiment polarity associated. These tags showed $70.4 \%$ of participants describing their trips using tags with either positive or neutral polarity.

Considering that sentiment polarity is related to participants' satisfaction with cycling, we compared the tags recorded in the collaboration and competition condition (see Fig. 3). As the figure shows, the collaboration condition concentrated the tags mostly in the first ten days of the campaign while the competition concentrated them after day 10. Although participants recorded most of the tags during the first two weeks, 25 per day on average, there were differences between the competition condition, 476 
tags, and the collaboration condition, 315 tags. Besides, there were significant differences between cities. While in Malta participants recorded 430 tags and in Castelló 252, participants in Münster recorded 109 tags.

The detail study of the tags recorded during the first two weeks revealed 177 positive tags ( 96 collaboration, 81 competition), 128 neutral tags (57 collaboration, 71 competition), and 68 negative tags (38 collaboration, 30 competition). This distribution suggests a slightly higher level of satisfaction in the collaboration condition during the experiment. However, Fig. 3 shows how this trend produced more tags recorded as well as more tags with neutral and positive polarity in the competition condition after the experiment finished.

In addition to tag polarity, we checked tag frequency and meaning. Participants mostly referred to the higher speed of bicycles and the city environment, see Table 7. "Fast" was the most recorded tag among participants along with similar terms such as "quick", "speedy", "efficient" and "moving". All of these terms referring to cycling speed are in the top ten. Additionally, among the 20 most reported tags, we found tags such as "relaxed", "secure", "inspiring", "crowded", "risky" and "safe"; referring to the city cycling environment.

\section{Engagement with cycling during the experiment}

To measure participants' engagement with cycling, we used the number of trips recorded during the experiment. The participants recorded 793 trips not only during the time of the experiment but also after it finished. Although participants had the instruction to record trips for one week, 21 participants recorded 172 trips after the experiment. From these 21, 18 participants (11 from Castellón, 4 from Malta, and 3 from Münster) even recorded trips after the third week. Consequently, we analysed the trips in two scenarios: the trips recorded during the experiment to equally compare 
participants from the three cities (457); and all recorded trips (793) which include the extreme participants. On average, participants recorded 9.3 trips during the experiment, 15 trips in total. The average increased with the trips recorded after the experiment in Castelló and Malta since in Münster participants recorded fewer trips, see Fig. 4. Overall, these figures are an indicator of engagement of the participants during the experiment.

There were differences between the two experimental conditions regarding the number of trips recorded. During the first two weeks of the experiment, participants from the collaboration condition (321 trips) recorded slightly more trips than participants from the competition condition (298 trips). However, when considering the total number of trips recorded, participants from the competition condition kept recording trips for up to six weeks and, therefore, recorded a higher number of trips recorded.

According to the classification proposed for data analysis (see satisfaction with cycling), there were 347 trips (43.8\%) valid, 204 trips (25.7\%) valid in time, 34 trips (4.3\%) valid in distance, and 208 trips (26.3\%) invalid. Trips were classified in such a way after deleting records from participants who experienced crashing of the application or recorded an incorrect number of trips at the three cities (4 participants in Münster, 6 in Castelló, and 2 in Malta).

Most of the participants' trips lasted less than 30 minutes, but participants from the collaboration condition usually recorded shorter trips than those in the competition condition. The trips from the collaboration condition usually lasted about five minutes, while the trips from the competition condition lasted between 10 and 20 minutes. As a result, the trips from the former case were shorter than the trips in the later. Finally, comparing cycling distances, the trips from the collaboration condition were usually 
shorter than 3 kilometres, while the trips from the competition condition were between 5 and 10 kilometres.

\section{Discussion}

The slightly higher satisfaction with cycling, as well as the higher number of trips recorded during the experiment by participants from the collaboration condition, are an indication that collaboration-based incentives deserve more attention from researchers (and practitioners) on persuasive technologies for urban cycling. We found indications that collaboration-based rewards expressed as higher percentages given to participants recording more trips and tags in our mobile gamified application produced higher levels of satisfaction and engagement with urban cycling than competition-based rewards. However, when it comes to the effectiveness of the application in actually persuading participants to change their behaviour, we found that interacting for just one week with a mobile application may not be enough to change participants' worldview of cycling as a regular mode of transport.

\section{Collaboration as one parameter of urban cycling applications}

When comparing participants' enjoyment between the two experimental conditions (Question Collaboration Condition: "I found collaborating with other cyclists enjoyable". Question Competition Condition: "I found competing against other cyclists enjoyable"), participants from the collaboration condition reported a significantly higher enjoyment than participants from the competition condition (mean collaboration: 2.269 , mean competition: -0.679 . Wilcoxon Test: $\mathrm{W}=688, \boldsymbol{p}<0.001)$. Results from the three cities follow the same pattern as seen in Fig. 5. This result speaks in favour of collaboration as one parameter for customized persuasion in urban cycling applications. This challenges mobile application providers and developers to rethink their strategies 
as it suggests that there are cases where competition would not be the best option to make the cycling experience most enjoyable.

\section{Lessons learned on engaging participants for cycling through mobile LBS}

Besides testing our hypothesis, the experiment allowed us to confirm, at a small scale, some of our design assumptions. Although the use of short campaigns may not lead to a deep change in participants' worldview of cycling, they offered us a convenient environment to involve participants with data collection without changing their commuting routine. The use of mobile technologies for data collection allowed participants to create a substantial, high-quality dataset that is useful for further analysis of patterns of urban cycling.

We found different levels of engagement with cycling in the two conditions. Participants from the collaboration condition seemed slightly more engaged in cycling because of the higher number of trips recorded during the first two weeks, while participants from the competition condition tended to record trips after the experiment. We observed some possible effects of the two approaches: i) collaboration might increase the engagement with cycling only in cases when it is clear that there are enough participants to collaborate with, and ii) competition might help to produce more data since participants want to see themselves first on the leader board. We need further experiments to better understand and describe the effects of strategies based on collaboration and competition in citizen engagement with urban cycling.

\section{Participant background effects}

Although most of the participants occasionally commuted by bicycle, in Münster we found that 10 out of the 20 recruited participants were bicycle- only commuters. Fig. 6 shows how the participants from Valletta and Castellón combined the bicycle with other 
means of transportation. When asked for the modes of transport used in the city, 55 participants (96\%) chose the bicycle, $28(49.1 \%)$ walking, $20(35.1 \%)$ their private car, and $19(33.3 \%)$ public transport. Seventeen participants (29.8\%) reported "bicycle" as their only mode of commuting.

Comparing the bicycle trips across the three cities, Münster had the highest bicycle modal share and the lowest average of trip's length and duration. The differences in length and duration of trips may be related to the purpose and frequency of the trips. The short trips in Münster (3075.4m, $34.4 \mathrm{~min})$ could mean that participants cycle more inside the urban area, while in Malta (5204.2m, 27.4 min) and Castelló (7815.6m, $20.9 \mathrm{~min}$ ) participants tend to use the bicycle just to reach their working/studying places and not for other short trips to connecting places within the city. Modal share, length, and duration of the trips are three fundamental indicators to describe mobility. However, to better describe the differences between the three cities, future research should include the analysis of urban morphology and a more detailed description of the purposes, origins, and destinations of the trips.

Participants' background and their relationship with members of the cycling advocacy groups might influence their levels of satisfaction, intentions and engagement with cycling. The answers in pre-questionnaires show their confidence by disagreeing with statements such as "too much physical effort", "too long", or "my bike at risk of being stolen while is parked". Additionally, they were more neutral about statements referring to cycling infrastructure which meant potential difficulties "negotiating with other actors in complex intersections and junctions" or using "existing roads". Despite their commitment to cycle, they agreed on the safety associated with having more cycle lanes. The details of the participants' answers are in Fig. 7. 
Although we found more than one-half of participants (60\%) already using mobile applications for cycling, the combination of a simplified interface and the extra task of recording every single trip might have decreased participants' satisfaction while using our app. Also, since neither Strava nor any of the mobile applications reported by participants to record and share sports activities focused on urban cycling, it could make participants forget to record their commuting trips, since they used such tracking applications during weekend or during training times.

When asked for the use of mobile phones, we saw participants mainly using them for communication and playing very few mobile games. Out of the total, 54 participants (94.7\%) used it for basic applications and messaging, 37 (64.9\%) for news, $32(40.4 \%)$ for productivity applications and just $11(19.3 \%)$ for mobile games. These figures evidence that urban cycling applications are not yet general purpose solutions and, due to the specific needs of their users, they might need an enhanced user experience to attract greater adoption and usage.

\section{Limitations}

One limitation faced during the experiment referred to the minimalistic design and the technical failures of our mobile application. Some participants did not finish the experiment (either because they did not use the bicycle during the experiment time or were unable to meet the researchers for the second time), and other participants forgot to record some trips. In addition, participants suggested some features which would have improved their overall interaction with the geo-game or the qualitative feedback provided after the experiment. Example of features mentioned by the users included: personalised reminders to record trips, personalised tags, and a map view of the trips with the geographic context of cycling. Despite these suggestions for improvement, participants showed a real interest in contributing not only to the experiment but also to 
the promotion of urban cycling. They collected data at each city and demonstrated a willingness to promote urban cycling as well as to share its benefits.

Another limitation may be related to the type of people who participated in the experiment. The very fact that participants volunteered to invest their time for the experiment, may be an indication of altruistic behaviour, and possibly linked back to their propensity to 'collaborate with' rather than 'compete against' others. This aspect was not measured during the experiment. Replicating the study assessing the participants' natural inclination to collaboration or competition in future work (e.g., by asking them to report on the last time they participated in a completion/collaboration project in their free time, and how often they do this) could help further clarify the scope of applicability of the findings (i.e., which part of the population do they exactly apply to).

\section{Conclusions}

Urban cycling is an important mode of transportation for cities and is poised to grow further. Although current mobile applications for cyclists use competition as the main social persuasion strategy, there is still a need to understand the most appropriate incentives to engage cyclists in urban contexts. Our study provided insights into collaboration-based incentives as a relevant source of motivation for urban cyclists. We tested 57 participants in three European cities: Münster (Germany), Castelló (Spain), and Valletta (Malta). The experiment compared the impact of collaboration-based and competition-based rewards on participants' enjoyment, satisfaction, engagement with, and intention to cycle.

Our results showed that participants reported higher enjoyment and engagement with cycling during the experiment in the collaboration condition. Besides, the participants 
generated potentially useful geospatial information describing the cycling patterns in three European cities.

The experiment implemented a successful approach to collect data on urban cycling without changing participants' commuting routines. However, the experiment did not have an impact on participants' intention to cycle, probably due to the short period (i.e., one week) of the study. We discovered several directions for future work: i) explore the factors which might lead to changes in perceptions of urban cycling; ii) evaluate the impact of virtual rewards in satisfaction and engagement with urban cycling during longer periods; iii) explore the impact of gamified strategies on participants with no-cycling background or at very initial stages of commuting by bicycle; and iv) investigate ways to translate collaboration strategies into user interfaces and virtual rewards to enhance users' experience.

Future works should also consider more diverse groups of cyclists to contrast our results: non-cyclists, occasional cyclists, and people starting to commute by bicycle would help to better understand the preferences for either competition or collaboration approaches.

\section{Acknowledgements}

Authors of this document gratefully acknowledge funding from the European Union through the GEO-C project (H2020-MSCA-ITN-2014, Grant Agreement Number 642332, http://www.geoc.eu/); from the Citizen Science COST Action CA15212 www.cs-eu.net; and from the small bursary provided by the Association of Geographic Information Laboratories in Europe AGILE for gathering research data. Authors also acknowledge the relevant suggestions from Dr. Carlos Granell for the final version of the paper. The experiment was approved by the Committee of Ethics at Universitat Jaume I and the Committee of Ethics at the Institute for Geoinformatics, University of Münster.

\section{References}

Abu-Sharkh, O. M. F., \& Dabain, Z. (2016). GreenBikeNet: an Intelligent Mobile 
Application with Green Wireless Networking for Cycling in Smart Cities. Mobile Networks and Applications, 21(2), 352-366. https://doi.org/10.1007/s11036-0150652-x

Albrecht, R., Väänänen, R., \& Lokki, T. (2016). Guided by music: pedestrian and cyclist navigation with route and beacon guidance. Personal and Ubiquitous Computing, 20(1), 121-145. https://doi.org/10.1007/s00779-016-0906-z

Attard, M., Haklay, M., \& Capineri, C. (2016). The Potential of Volunteered Geographic Information (VGI) in Future Transport Systems. Urban Planning, 1(4), 6. https://doi.org/10.17645/up.v1i4.612

Ayuntament de Castelló. (2016). PLAN DIRECTOR DE LA BICICLETA DE CASTELLÓN. Retrieved from http://www.castello.es/web20/archivos/menu3/154/Memoria_PDBC.pdf

Barratt, P. (2017). Healthy competition: A qualitative study investigating persuasive technologies and the gamification of cycling. Health and Place, 46, 328-336. https://doi.org/10.1016/j.healthplace.2016.09.009

Bigazzi, A. Y. (2017). Determination of active travel speed for minimum air pollution inhalation. International Journal of Sustainable Transportation, 11(3), 221-229. https://doi.org/10.1080/15568318.2016.1238984

Bonham, J., \& Johnson, M. (2015). Cycling: Bringing the future into the present. In R. Burton (Ed.), Cycling futures (pp. 3-23). Retrieved from http://dro.deakin.edu.au/view/DU:30080904

Braun, L. M., Rodriguez, D. A., Cole-Hunter, T., Ambros, A., Donaire-Gonzalez, D., Jerrett, M., ... de Nazelle, A. (2016). Short-term planning and policy interventions to promote cycling in urban centers: Findings from a commute mode choice analysis in Barcelona, Spain. Transportation Research Part A: Policy and Practice, 89, 164-183. https://doi.org/10.1016/j.tra.2016.05.007

Calvey, J. C., Shackleton, J. P., Taylor, M. D., \& Llewellyn, R. (2015). Engineering condition assessment of cycling infrastructure: Cyclists' perceptions of satisfaction and comfort. Transportation Research Part A: Policy and Practice, 78, 134-143. https://doi.org/10.1016/j.tra.2015.04.031

Carlsson, C. (2002). Critical mass : bicycling's defiant celebration. Retrieved from 
https://books.google.es/books?hl=en\&lr=\&id=iVpHsLMgiCcC\&oi=fnd\&pg=PA5 $\& d q=$ cycling+critical+mass + citizens $+\& o t s=S r 2 I 22 P Q 5 f \& s i g=D I W e 51-$ nGGwyMgRA-lTOXUgJiEs\#v=onepage $\& \mathrm{q}=$ cycling critical mass citizens $\& \mathrm{f}=$ false

Cervero, R., Sarmiento, O. L., Jacoby, E., Gomez, L. F., \& Neiman, A. (2009).

Influences of Built Environments on Walking and Cycling: Lessons from Bogotá. International Journal of Sustainable Transportation, 3(4), 203-226. https://doi.org/10.1080/15568310802178314

Chen, P., Shen, Q., \& Childress, S. (2018). A GPS data-based analysis of built environment influences on bicyclist route preferences. International Journal of Sustainable Transportation, 12(3), 218-231. https://doi.org/10.1080/15568318.2017.1349222

Claudel, M., Nagel, T., \& Ratti, C. (2016). From Origins to Destinations : The Past, Present and Future of Visualizing Flow Maps. Built Environment, 42(3), 338-355. Retrieved from http://www.alexandrinepress.co.uk/Announcing-Big-Data-Issue Degbelo, A., Bhattacharya, D., Granell, C., \& Trilles, S. (2016). Toolkits for smarter cities: A brief assessment. In C. R. García, P. Caballero-Gil, M. Burmester, \& A. Quesada-Arencibia (Eds.), Lecture Notes in Computer Science (including subseries Lecture Notes in Artificial Intelligence and Lecture Notes in Bioinformatics): Vol. 10070 LNCS (pp. 431-436). https://doi.org/10.1007/978-3-319-48799-1_47

Degbelo, A., Granell, C., Trilles, S., Bhattacharya, D., Casteleyn, S., \& Kray, C. (2016). Opening up Smart Cities: Citizen-Centric Challenges and Opportunities from GIScience. ISPRS International Journal of Geo-Information, 5(2), 16. https://doi.org/10.3390/ijgi5020016

Dill, J., \& McNeil, N. (2012). FOUR TYPES OF CYCLISTS? Testing a Typology to Better Understand Bicycling Behavior and Potential. Retrieved from OTREC PSU website: http://web.pdx.edu/ jdill/Types_of_Cyclists_PSUWorkingPaper.pdf

Fyhri, A., Heinen, E., Fearnley, N., \& Sundfør, H. B. (2017). A push to cyclingexploring the e-bike's role in overcoming barriers to bicycle use with a survey and an intervention study. International Journal of Sustainable Transportation, 11(9), 681-695. https://doi.org/10.1080/15568318.2017.1302526

Garrard, J. (2015). Evaluating cycling promotion interventions. In R. Burton (Ed.), 
Cycling Futures (pp. 429-452). https://doi.org/10.1038/165060c0

Gatersleben, B., \& Haddad, H. (2010). Who is the typical bicyclist? Transportation Research Part F: Traffic Psychology and Behaviour, 13(1), 41-48. https://doi.org/10.1016/j.trf.2009.10.003

Gehan, E. A. (1965). A generalized Wilcoxon test for comparing arbitrarily singlycensored samples. Biometrika, 52(1-2), 203-224. https://doi.org/10.1093/biomet/52.1-2.203

Gössling, S. (2018). ICT and transport behavior: A conceptual review. International Journal of Sustainable Transportation, 12(3), 153-164. https://doi.org/10.1080/15568318.2017.1338318

Haklay, M. (2013). Citizen science and volunteered geographic information: Overview and typology of participation. In Crowdsourcing Geographic Knowledge: Volunteered Geographic Information (VGI) in Theory and Practice (Vol. 9789400745, pp. 105-122). https://doi.org/10.1007/978-94-007-4587-2_7

Halko, S., \& Kientz, J. A. (2010). Personality and Persuasive Technology: An Exploratory Study on Health-Promoting Mobile Applications (T. Ploug, P. Hasle, \& H. Oinas-Kukkonen, eds.). In (pp. 150-161). https://doi.org/10.1007/978-3-64213226-1_16

Handy, S., van Wee, B., \& Kroesen, M. (2014). Promoting Cycling for Transport: Research Needs and Challenges. Transport Reviews, 34(1), 4-24. https://doi.org/10.1080/01441647.2013.860204

Hood, J., Sall, E., \& Charlton, B. (2011). A GPS-based bicycle route choice model for San Francisco, California. Transportation Letters, 3(1), 63-75. https://doi.org/10.3328/TL.2011.03.01.63-75

Horton, D. (2006). Environmentalism and the bicycle. Environmental Politics, 15(1), 41-58. https://doi.org/10.1080/09644010500418712

Lakens, D. (2013). Calculating and reporting effect sizes to facilitate cumulative science: a practical primer for t-tests and ANOVAs. Frontiers in Psychology, 4, 863. https://doi.org/10.3389/fpsyg.2013.00863

Land Transport Authority. (2013). Land Transport Master Plan. Retrieved October 12, 2017, from http://www.transport.gov.mt/admin/uploads/media- 
library/files/Transport Master Plan rev 2.0.pdf

Likert Rensis. (1932). A technique for the measurement of attitudes. 22(144), 55.

Retrieved from http://psycnet.apa.org/record/1933-01885-001

Lydon, M., Garcia, T., Flynn, J., Murriente, S., Wall, D., \& Simpson, C. (2016).

Tactical Urbanist's Guide. Retrieved from http://tacticalurbanismguide.com/

Martinez Tabares, C. (2017). Individual Factors Related to Utilitarian Urban Cycling: Representations, Motivations and Perceived Aggression. Université Paris VIII Vincennes-Saint-Denis.

McNutt, K. (2014). Public engagement in the Web 2.0 era: Social collaborative technologies in a public sector context. Canadian Public Administration, 57(1), 49-70. https://doi.org/10.1111/capa.12058

Miller, H. J. (2013). Beyond sharing: cultivating cooperative transportation systems through geographic information science. Journal of Transport Geography, 31, 296-308. https://doi.org/10.1016/J.JTRANGEO.2013.04.007

Miller, H. J., \& Shaw, S.-L. (2001). Geographic Information Systems for Transportation: Principles and Applications. Retrieved from https://global.oup.com/academic/product/geographic-information-systems-fortransportation-9780195123944

Montini, L., Prost, S., Schrammel, J., Rieser-Schüssler, N., \& Axhausen, K. W. (2015). Comparison of travel diaries generated from smartphone data and dedicated GPS devices. Transportation Research Procedia, 11, 227-241. https://doi.org/10.1016/j.trpro.2015.12.020

Münster Stadt. (2017). Bicyles in Münster. Retrieved February 12, 2018, from http://www.stadt-muenster.de/english/transport/bicycles.html

National Geospatial Advisory Committee. (2015). THE CHANGING GEOSPATIAL LANDSCAPE A Second Look. Retrieved from https://www.fgdc.gov/ngac/meetings/december-2015/the-changing-geospatiallandscape-second-look.pdf

Navarro, K. F., Gay, V., Golliard, L., Johnston, B., Leijdekkers, P., Vaughan, E., ... Williams, M. A. (2013). SocialCycle: What can a mobile app do to encourage cycling? Proceedings - Conference on Local Computer Networks, LCN, 24-30. 
https://doi.org/10.1109/LCNW.2013.6758494

Nielsen, T. A. S., Skov-Petersen, H., \& Agervig Carstensen, T. (2013). Urban planning practices for bikeable cities - the case of Copenhagen. Urban Research \& Practice, 6(1), 110-115. https://doi.org/10.1080/17535069.2013.765108

Norris, J. (2015). Future Trends in geospatial information management: the five to ten year vision. Retrieved from http://ggim.un.org/documents/UN-GGIM-Futuretrends_Second_edition.pdf

Oldenziel, R., Emanuel, M., de la Bruheze, A. A. A., \& Veraart, F. (2015). Cycling Cities: The European Experience. Retrieved from http://www.cyclingcities.info/ op den Akker, H., Jones, V. M., \& Hermens, H. J. (2014). Tailoring real-time physical activity coaching systems: a literature survey and model. User Modeling and UserAdapted Interaction, 24(5), 351-392. https://doi.org/10.1007/s11257-014-9146-y

Pajarito, D., \& Gould, M. (2017). Smart Mobility, the Role of Mobile Games. In A. M, G. S, M. M, F. O. M., B. H. J, \& M. T. (Eds.), Lecture Notes in Computer Science (10622nd ed., pp. 44-59). https://doi.org/10.1007/978-3-319-70111-0_5

Pang, B., \& Lee, L. (2008). Opinion Mining and Sentiment Analysis. Foundations and Trends in Information Retrieval, 2(1-2), 1-135. https://doi.org/10.1561/1500000001

Pooley, C. G., Jones, T., Horton, D., Jopson, A., Mullen, C., Chisholm, A., \& Constantine, S. (2011). Understanding walking and cycling: Summary of key findings and recommendations. Retrieved from http://eprints.lancs.ac.uk/50409/1/Understanding_Walking_Cycling_Report.pdf\%5 Cnhttp://eprints.lancs.ac.uk/50409/1/Understanding_Walking_Cycling_Report.pdf

Pucher, J., \& Buehler, R. (2008). Making Cycling Irresistible: Lessons from The Netherlands, Denmark and Germany. Transport Reviews, 28(4), 495-528. https://doi.org/10.1080/01441640701806612

Pucher, J., \& Buehler, R. (2017). Cycling towards a more sustainable transport future. Transport Reviews, 1-6. https://doi.org/10.1080/01441647.2017.1340234

Pucher, J., Dill, J., \& Handy, S. (2010). Infrastructure, programs, and policies to increase bicycling: An international review. Preventive Medicine, 50(SUPPL.). https://doi.org/10.1016/j.ypmed.2009.07.028 
Segadilha, A. B. P., \& Sanches, S. da P. (2014). Analysis of Bicycle Commuter Routes Using GPSs and GIS. Procedia - Social and Behavioral Sciences, 162, 198-207. https://doi.org/10.1016/j.sbspro.2014.12.200

Shapiro, S. S., \& Wilk, M. B. (1965). An Analysis of Variance Test for Normality (Complete Samples). Biometrika, 52(3/4), 591. https://doi.org/10.2307/2333709

Shin, D., Aliaga, D., Tunçer, B., Arisona, S. M., Kim, S., Zünd, D., \& Schmitt, G. (2015). Urban sensing: Using smartphones for transportation mode classification. Computers, Environment and Urban Systems, 53, 76-86. https://doi.org/10.1016/j.compenvurbsys.2014.07.011

Spillers, F., \& Asimakopoulos, S. (2014). Does Social User Experience Improve Motivation for Runners? In M. A. (Ed.), Lecture Notes in Computer Science (including subseries Lecture Notes in Artificial Intelligence and Lecture Notes in Bioinformatics): Vol. 8520 LNCS (8520th ed., pp. 358-369). https://doi.org/10.1007/978-3-319-07638-6_35

Stein, C. (1945). A Two-Sample Test for a Linear Hypothesis Whose Power is Independent of the Variance. The Annals of Mathematical Statistics, 16(3), 243258. https://doi.org/10.2307/2235703

Sultan, J., Ben-haim, G., Haunert, J., \& Dalyot, S. (2015, December). Using Crowdsourced Volunteered Geographic Information for Analyzing Bicycle Road Networks. International Federation of Surveyors, Article of the Month-December 2015 Using, (December), 1-14. Retrieved from http://www.fig.net/resources/monthly_articles/2015/december_2015/Sultan_etal_d ecember_2015.pdf

Tomitsch, M., \& Haeusler, M. H. (2015). Infostructures: Towards a Complementary Approach for Solving Urban Challenges through Digital Technologies. Journal of Urban Technology, 22(3), 37-53. https://doi.org/10.1080/10630732.2015.1040296

Torres, A., Sarmiento, O. L., Stauber, C., \& Zarama, R. (2013). The Ciclovia and Cicloruta programs: promising interventions to promote physical activity and social capital in Bogotá, Colombia. American Journal of Public Health, 103(2), e23-30. https://doi.org/10.2105/AJPH.2012.301142

Waag Society. (2018). Making Sense. Retrieved from Making Sense website: 
http://making-sense.eu/contact/

Wang, H., Palm, M., Chen, C., Vogt, R., \& Wang, Y. (2016). Does bicycle network level of traffic stress (LTS) explain bicycle travel behavior? Mixed results from an Oregon case study. Journal of Transport Geography, 57, 8-18. https://doi.org/10.1016/j.jtrangeo.2016.08.016

Wojan, T. R., \& Hamrick, K. S. (2015). Can Walking or Biking to Work Really Make a Difference? Compact Development, Observed Commuter Choice and Body Mass Index. PloS One, 10(7), e0130903. https://doi.org/10.1371/journal.pone.0130903

Wolff, A., Valdez, A.-M., Barker, M., Potter, S., Gooch, D., Giles, E., \& Miles, J. (2017). Engaging with the Smart City Through Urban Data Games (A. Nijholt, Ed.). In (pp. 47-66). https://doi.org/10.1007/978-981-10-1962-3_3

Yeboah, G., \& Alvanides, S. (2015). Route choice analysis of urban cycling behaviors using OpenStreetMap: evidence from a British urban environment. In OpenStreetMap in GIScience (pp. 189-210). https://doi.org/10.1007/978-3-31914280-7_10

Zahabi, S. A. H., Chang, A., Miranda-Moreno, L. F., \& Patterson, Z. (2016). Exploring the link between the neighborhood typologies, bicycle infrastructure and commuting cycling over time and the potential impact on commuter GHG emissions. Transportation Research Part D: Transport and Environment, 47, 89103. https://doi.org/10.1016/j.trd.2016.05.008

Zeile, P., Resch, B., Loidl, M., Petutschnig, A., \& Dörrzapf, L. (2016). Urban Emotions and Cycling Experience - enriching traffic planning for cyclists with human sensor data. Journal for Geographic Information Science - GI_Forum, 1(2013), 204-216. https://doi.org/10.1553/giscience2016_01_s204 
Table 1. List of existing applications for cyclists.

\begin{tabular}{|l|c|c|c|c|}
\cline { 2 - 5 } & \multirow{2}{*}{} & \multicolumn{2}{|c|}{ Type of cycling } & \multicolumn{2}{c|}{ Gamification Strategies } \\
\cline { 2 - 5 } & Urban & Sport & Collaboration & Competition \\
\hline Strava & & $\mathrm{X}$ & $\mathrm{X}$ & $\mathrm{X}$ \\
\hline Map My Ride & & $\mathrm{X}$ & $\mathrm{X}$ & $\mathrm{X}$ \\
\hline Runtastic & & $\mathrm{X}$ & & $\mathrm{X}$ \\
\hline Endomondo & & $\mathrm{X}$ & & $\mathrm{X}$ \\
\hline Human & & $\mathrm{X}$ & & $\mathrm{X}$ \\
\hline Cycle Map & $\mathrm{X}$ & & & $\mathrm{X}$ \\
\hline VeloPal & & $\mathrm{X}$ & & $\mathrm{X}$ \\
\hline Google fit & & $\mathrm{X}$ & & $\mathrm{X}$ \\
\hline Apple Health & & $\mathrm{X}$ & & $\mathrm{X}$ \\
\hline Bike Citizens & $\mathrm{X}$ & & $\mathrm{X}$ & $\mathrm{X}$ \\
\hline Biko & $\mathrm{X}$ & & & $\mathrm{X}$ \\
\hline
\end{tabular}


Table 2. Independent and dependent variables of the study.

\begin{tabular}{|c|c|c|}
\hline Independent Variable & Dependent Variable & Measurement of dependent variables \\
\hline \multirow{4}{*}{$\begin{array}{l}\text { Type of reward: } \\
\text { a. Collaboration-based } \\
\text { b. Competition-based }\end{array}$} & Intention to cycle & $\begin{array}{l}\text { Comparison of answers to "My intention to use a bicycle is" using } \\
\text { the scale: } \\
\text { "Very Weak" (-3) "neutral" (0), "Very Strong" (3) }\end{array}$ \\
\hline & Satisfaction with cycling & $\begin{array}{l}\text { 1) Answers to the question "Indicate how satisfied / dissatisfied } \\
\text { in general you were with: cycling during the experiment" using } \\
\text { the scale: } \\
\text { "Very dissatisfied" (-3), "Very satisfied" (3) } \\
\text { 2) Comparison of tags' sentiment polarity. }\end{array}$ \\
\hline & Engagement with cycling & $\begin{array}{l}\text { 1) Number of trips recorded during and after the experiment. } \\
\text { 2) Number of tags recorded during and after the experiment. }\end{array}$ \\
\hline & $\begin{array}{l}\text { Enjoyment with } \\
\text { collaboration or competition }\end{array}$ & $\begin{array}{l}\text { Answers to the question "I found collaborating with / competing } \\
\text { against other cyclists enjoyable" using the scale: } \\
\text { "Strongly disagree" (-3), "Strongly agree" (3) }\end{array}$ \\
\hline
\end{tabular}


Table 3. Demographic information of participants.

\begin{tabular}{|c|c|c|c|c|c|}
\hline & & Münster (Germany) & $\begin{array}{c}\text { Castellon } \\
\text { (Spain) }\end{array}$ & $\begin{array}{l}\text { Malta } \\
\text { (Malta) }\end{array}$ & Total \\
\hline \multicolumn{2}{|l|}{ Male } & 11 & 12 & 11 & 35 \\
\hline \multicolumn{2}{|l|}{ Female } & 9 & 8 & 6 & 24 \\
\hline \multirow{4}{*}{ Age } & Min. & 23.00 & 15.00 & 20.00 & - \\
\hline & Median & 32.00 & 36.50 & 28.00 & - \\
\hline & Mean & 31.55 & 36.35 & 32.12 & 33.43 \\
\hline & Max. & 38.00 & 46.00 & 58.00 & - \\
\hline \multirow{4}{*}{ Marital Status } & Single: & 6 & 9 & 8 & 23 \\
\hline & Not living together: & 6 & 3 & 3 & 12 \\
\hline & Living together: & 2 & 2 & 2 & 6 \\
\hline & Married: & 6 & 6 & 4 & 16 \\
\hline
\end{tabular}


Table 4. Participants' cycling profile.

\begin{tabular}{|l|r|r|r|}
\hline \multicolumn{1}{|c|}{ Question } & Castelló & Valletta & Münster \\
\hline I would find cycling enjoyable & 2.0 & 1.9 & 1.8 \\
\hline I would get a sense of freedom & 2.6 & 2.8 & 1.6 \\
\hline I would feel part of my community & 1.3 & 1.5 & 0.6 \\
\hline I would find it relaxing & 2.2 & 2.2 & 1.8 \\
\hline More cycle lanes would make me feel safer & 2.4 & 2.5 & 1.5 \\
\hline It would benefit my health & 3.0 & 2.8 & 2.2 \\
\hline I would save me money & 2.5 & 2.8 & 1.9 \\
\hline It would be a bad experience using the existing roads & 0.4 & 0.8 & -0.9 \\
\hline It would mean 'I contribute less to climate change' & 1.7 & 2.1 & 1.2 \\
\hline It would be too much physical effort & -1.1 & -1.8 & -2.0 \\
\hline It would more than likely expose me to wet or windy weather & 1.2 & 0.5 & 0.4 \\
\hline It would mean 'I contribute less to local air pollution' & 2.9 & 2.2 & 1.6 \\
\hline It would take me too long & -1.0 & -2.0 & -1.8 \\
\hline It would put my bike at risk of being stolen whilst parked & -0.3 & -0.8 & -1.2 \\
\hline It would mean I have to negotiate difficult road junctions & 0.0 & 0.9 & -1.4 \\
\hline Values: -3 stands for "strongly disagree" while 3 stands for "strongly agree" & & \\
\hline
\end{tabular}


Table 5. List of tags in the "Cyclists Geo-C" geo-game.

\begin{tabular}{|l|l|l|}
\hline Positive Tags & Neutral Tags & Negative Tags \\
\hline Fast & Moderated & Slow-moving \\
\hline Quick & Normal & Time-consuming \\
\hline Speedy & Average & Brake-intensive \\
\hline Inspiring & Relaxed & Dull \\
\hline Light & Worthy & Crowded \\
\hline Efficient & Enough & Disconnected \\
\hline Safe & & Dangerous \\
\hline Secure & & Risky \\
\hline Sheltered & & Hazardous \\
\hline
\end{tabular}


Table 6. Comparison of intentions to cycle before and after the experiment.

\begin{tabular}{|l|c|c|l|l|}
\hline & Mean Before & Mean After & Wilcoxon Test & Cohen's Test \\
\hline 'My intention to use a bicycle is' & 2.537 & 2.500 & $\begin{array}{l}\mathrm{W}=1512.5 \\
\boldsymbol{p}=0.8024\end{array}$ & $\begin{array}{l}\mathrm{d}=0.035 \\
\mathrm{Inf}=-0.3 \\
\text { Sup }=0.4\end{array}$ \\
\hline $\begin{array}{l}\text { My intention to use a bicycle is' } \\
\text { Collaboration condition }\end{array}$ & 2.577 & 2.423 & $\boldsymbol{p}=0.507$ & \\
\hline $\begin{array}{l}\text { 'My intention to use a bicycle is' } \\
\text { Competition condition }\end{array}$ & 2.500 & 2.571 & $\boldsymbol{p}=0.915$ & \\
\hline
\end{tabular}


Table 7. Top 20 Tags and Frequency.

\begin{tabular}{|c|l|c|c|l|c|}
\hline Position & \multicolumn{1}{|c|}{ Tag } & Frequency & Position & Tag & Frequency \\
\hline 1 & fast & 88 & 11 & worthy & 21 \\
\hline 2 & moderated & 65 & 12 & average & 20 \\
\hline 3 & normal & 42 & 13 & enough & 19 \\
\hline 4 & quick & 33 & 14 & inspiring & 17 \\
\hline 5 & speedy & 30 & 15 & light & 16 \\
\hline 6 & efficient & 28 & 16 & brake & 15 \\
\hline 7 & relaxed & 23 & 17 & crowded & 15 \\
\hline 8 & moving & 22 & 18 & intensive & 15 \\
\hline 9 & secure & 22 & 19 & risky & 14 \\
\hline 10 & slow & 22 & 20 & safe & 9 \\
\hline
\end{tabular}


Figure 1. Research method.

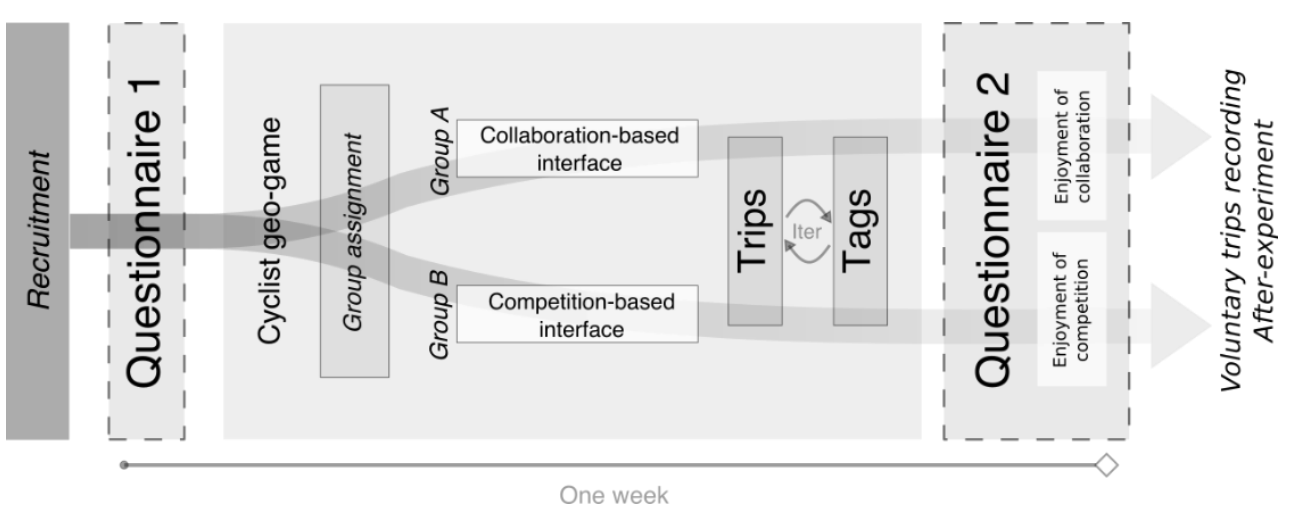


Figure 2. Mobile application interfaces for participants.

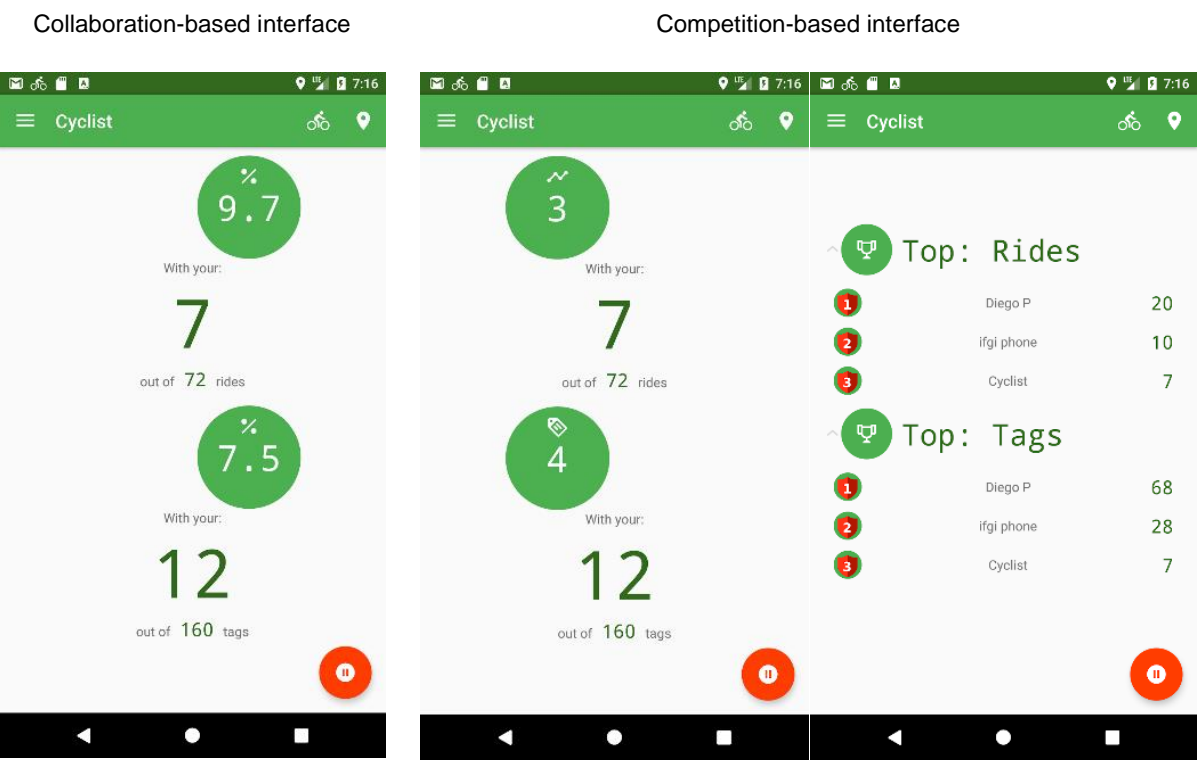


Figure 3. Tags recorded during the experiment in the two conditions. The campaign ended after day 10 .

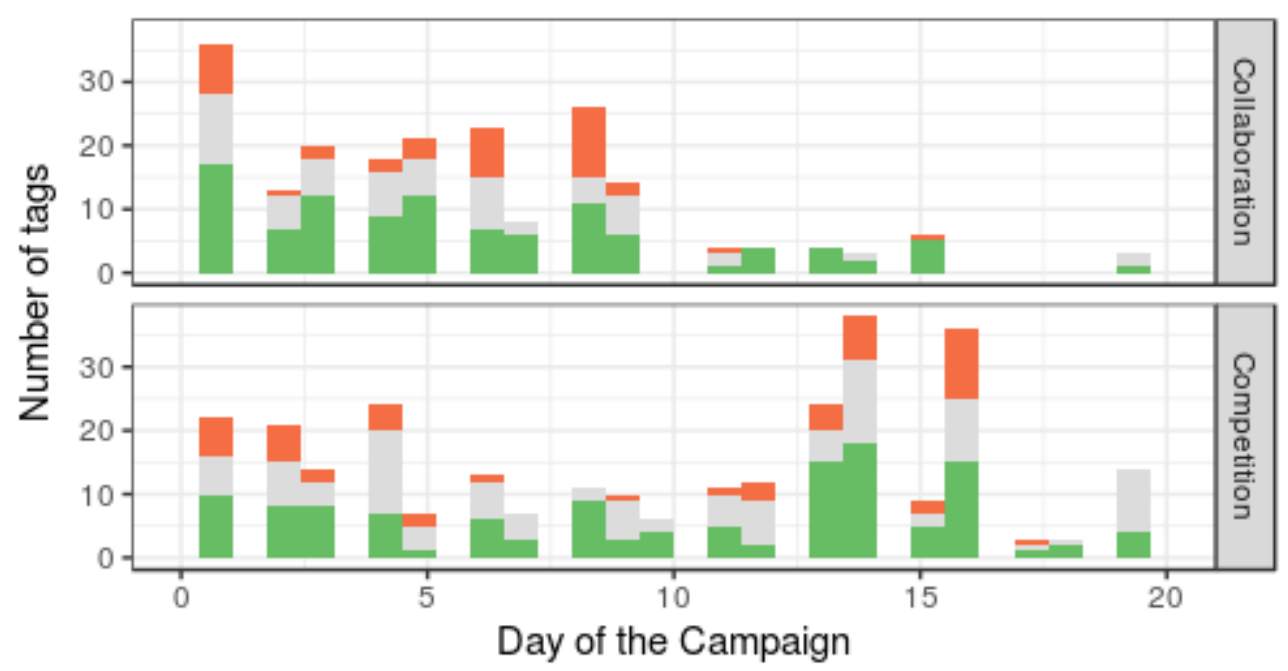

Sentiment Polarity Negative Neutral Positive 
Figure 4. Tags recorded
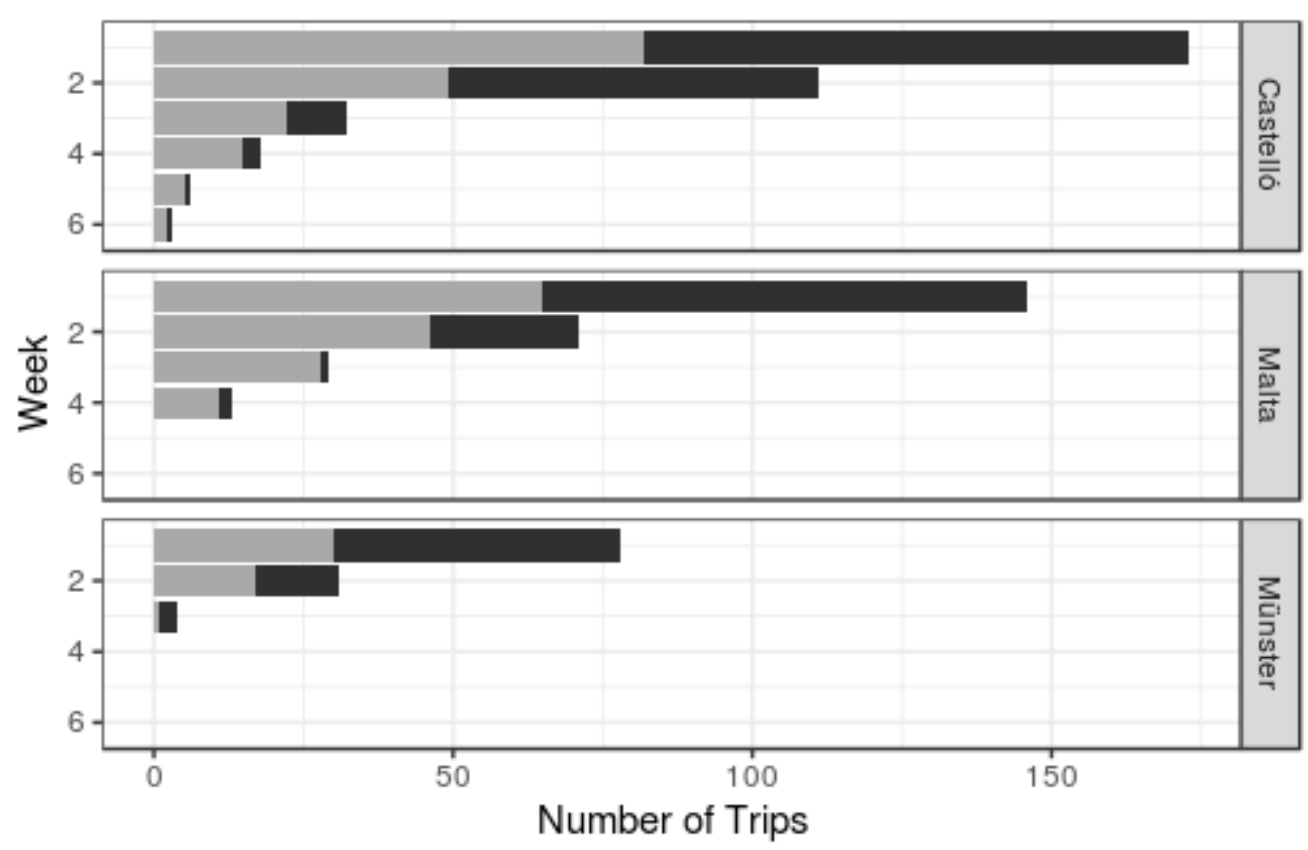

Condition Collaboration Competition 
Figure 5. Satisfaction with the motivation driving rewards

'I found ... other cyclists enjoyable'
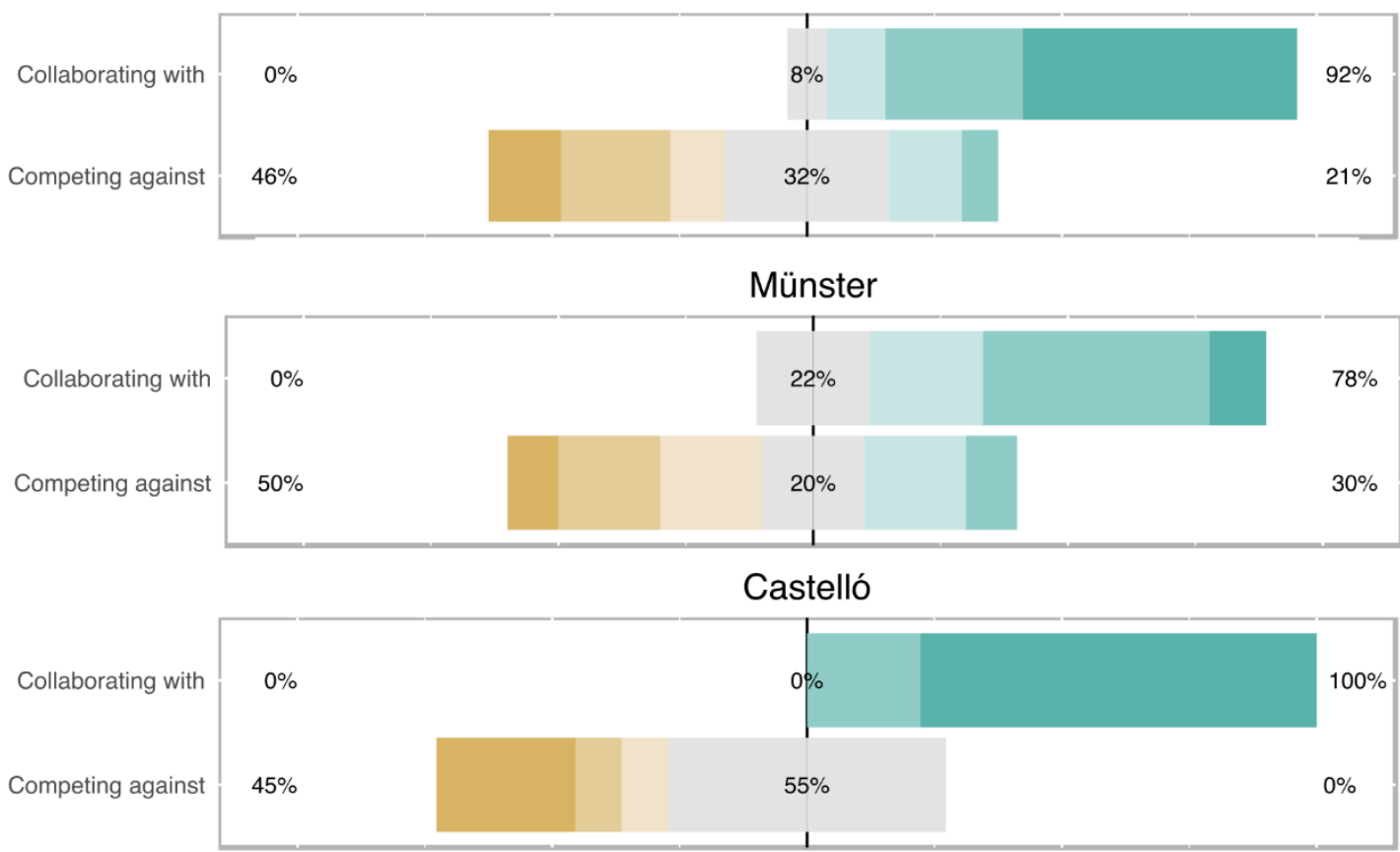

Valletta

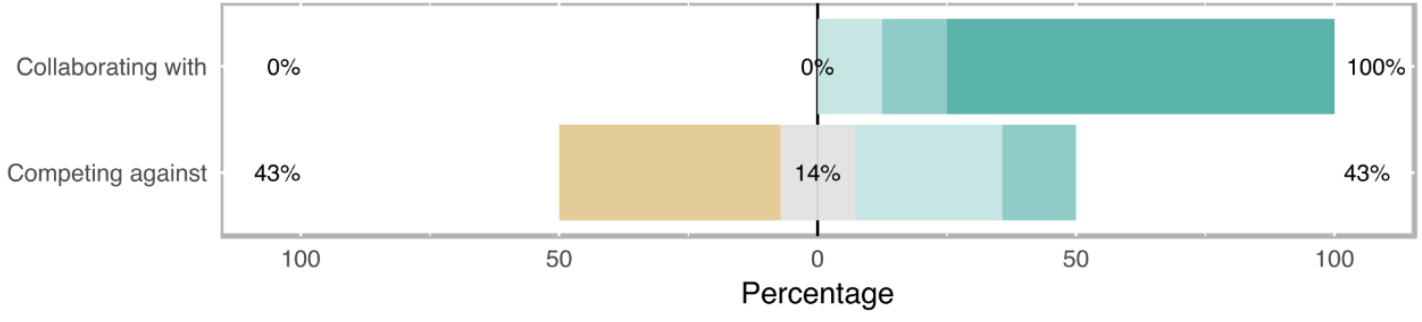

\begin{tabular}{|l|l|l|l|l|l|} 
Strongly disagree (-3) & $(-2)$ & $(-1) \quad$ Neutral (0) & (1)
\end{tabular} 
Figure 6. Participants' modes of transport used in the city

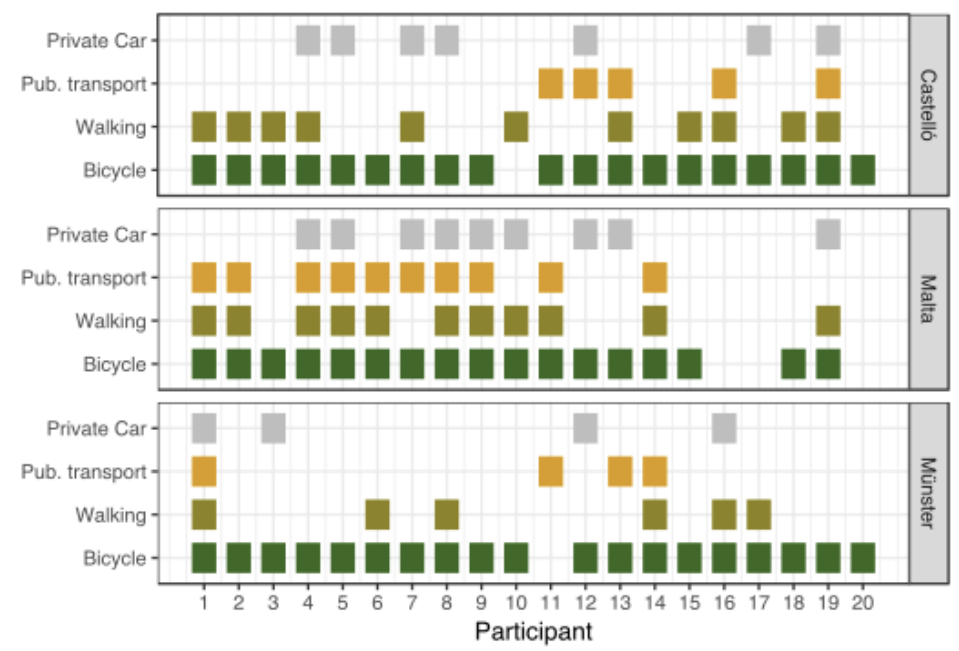


Figure 7. Perception of cycling infrastructure

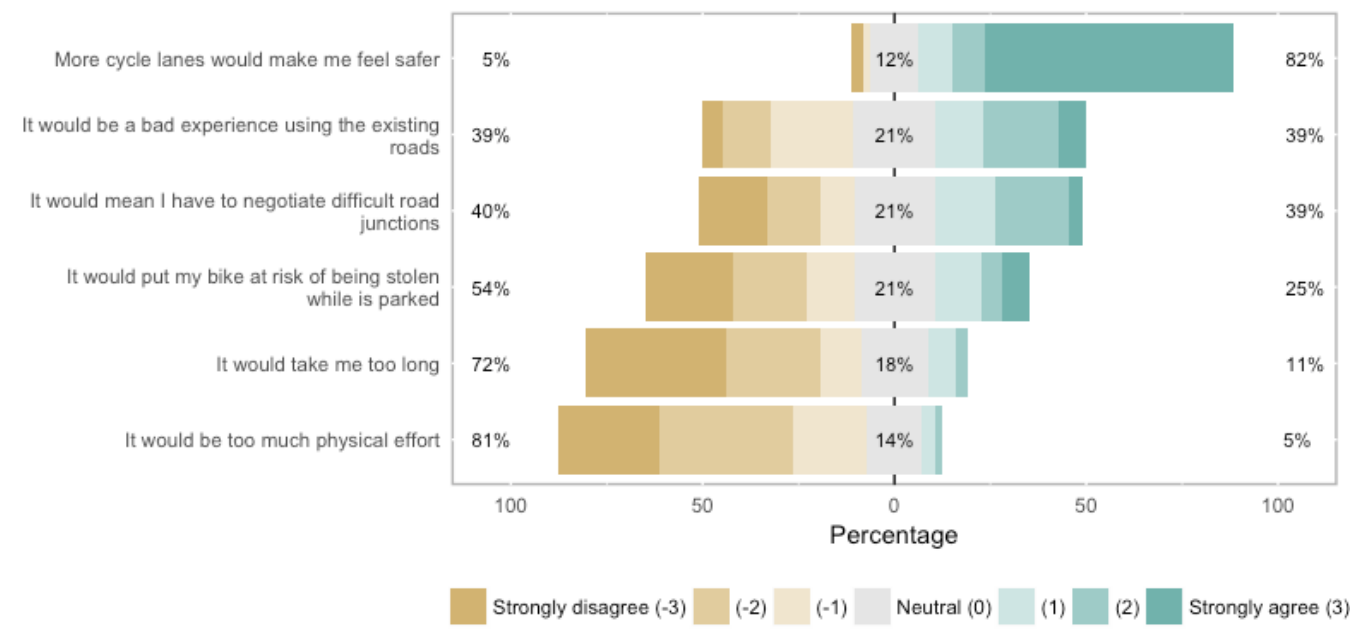

